\title{
From the Advisory Board
}

DOI: $10.1134 / \mathrm{S} 1023193508010011$

This issue of the Journal is dedicated to the centenary of the outstanding electrochemist Viktor Arturovich Pleskov. Professor Pleskov is famous for his works on the electrochemistry of nonaqueous solutions; in the first place his pioneer studies in the effects of solvent nature on the electrode potentials. He also did important research in other fields of electrochemistry. We open the issue with a biographic sketch on the life and works of Viktor Arturovich. The table of contents covers diverse aspects of the medium effects on the electrochemical processes, as well as some other problems of basic electrochemistry. The collaboration of all colleagues in this issue is gratefully acknowledged. 